\title{
Counseling of nursing mothers! How effective it is - For improving nutrition of neonates $\&$ infants
}

\author{
Sonwani $\mathbf{J}^{1}$, Mandliya $\mathbf{J}^{2}$, Nigam $\mathbf{K}^{3}$ \\ ${ }^{1}$ Dr Juhi Sonwani, PG Student, ${ }^{2}$ Dr Jagdish Mandliya, Associate professor, ${ }^{3}$ Dr Mrs. Kamna Nigam, Professor. All are \\ affiliated with department of Pediatrics, R. D. Gardi Medical College, Ujjain, MP, India.
}

Address for correspondence: Dr Juhi Sonwani, Email: blossomjuhi@yahoo.in

\begin{abstract}
Introduction: Optimal \& appropriate infant \& child feeding is one of the essentials to prevent morbidity \& mortality in neonates \& infants. The knowledge, practice \& skills of WHAT \& HOW of feeding must be known to every nursing mother. Counseling of mothers is one of the cost-effective approaches which can bring about a positive change in attitudes \& skills to improve nutrition of infants \& children. Aims \& Objectives: 1) Assess the knowledge \& attitude of nursing mothers regarding breast-feeding. 2) Observe breast-feeding skills. 3) Counseling \& post counseling assessment. Material \& Methods: Knowledge was assessed by questionnaire method of pretested proforma, Skill by observation of breastfeeding according to B-R-E-A-S-T proforma. One to one \& group counseling \& post-counseling assessment of mothers was done. Data was subjected to statistical analysis by SPSS 12 version \& McNemar test. Results: A total of 287 nursing mothers were studied, majority (94.4\%) between $20-30$ yrs of age, $92 \%$ Hindu, $63.8 \%$ from low socioeconomic status, $53.7 \%$ illiterate, $73.9 \%$ non-working, $63 \%$ from joint family\& only $16.7 \%$ received information on feeding from health-professionals. Knowledge: $23 \%$ of mothers gave correct answers to all questions related to breastfeeding. The average score of knowledge before counseling was 3.06 which increased to 9.87 post-counseling (pvalue $<0.01)$. Practice: The practice was poorer than knowledge; only $21.4 \%$ were practicing breast-feeding appropriately. Pre-counseling score 3.85 which increased to 8.41 post-counseling ( $p$-value $<0.00$ paired t-test). Skills: Pre-counseling score of 0.14 increased to 2.98 after counseling which was statistically highly significant ( $p$-value $<0.00)$. Conclusion: Inappropriate knowledge, practices \& incorrect skills on breast-feeding is still prevalent amongst mothers in general \& particularly in this area of Madhya-Pradesh. Repeated \& effective counseling appears to be only answer to improve infant-feeding.
\end{abstract}

Keywords: Breast feeding, Assessment, Skills, counseling

\section{Introduction}

Child survival lies at the heart of every scheme which aims to scale a proven high impact, cost-effective health $\&$ nutrition intervention to reduce the neonatal \& young child death. About $80 \%$ of health care in developing countries, including ours, occurs at home \& majority of children who die, do so at home, without being seen by health worker [1]. Appropriate breastfeeding \& infant feeding are still not practiced by many mothers. As many as $40 \%$ child deaths could be prevented by access only to solid knowledge \& support for infant feeding without high-tech health equipments.

Manuscript received: $25^{\text {th }}$ August 2015

Reviewed: $12^{\text {th }}$ September 2015

Author Corrected; $22^{\text {nd }}$ September 2015

Accepted for Publication: $5^{\text {th }}$ October 2015
Early initiation \& exclusive breast feeding improves newborn care \& reduces neonatal mortality which contributes to majority of infant deaths. Infant mortality can be readily reduced by about $13 \%$ with improving breast feeding practices alone \& 6\% with improved complimentary feeding [1]. In addition about $50-60 \%$ of under-five mortality is secondary to malnutrition, largely caused by inadequate complimentary feeding following on from poor breast feeding practices [1]. The global recommendations for optimal infant feeding include [2].

- Early initiation,

- exclusive breast feeding for the first six months, 
- introducing appropriate and adequate complementary feeding from six months along with continued breastfeeding,

- Continue breastfeeding till 2 years \& beyond.

The present study was undertaken to assess the precounseling knowledge, practices \& skills \& observe the change made by counseling in these recommendations.

\section{Aims and Objectives}

1. To assess the knowledge, attitude \& skills of nursing mothers on breastfeeding during immediate postnatal period.

2. Observe the mothers while feeding their infants for appropriate and effective attachment \& position.

3. Counseling \& post counseling assessment to see the change in knowledge, practice \& skills.

\section{Material \& Methods}

Study was undertaken in obstetric \& neonatal unit of $\mathrm{R}$ D GARDI medical college Ujjain Madhya-Pradesh (which caters mainly rural population), for a period of 1 year from January 2013 to December 2013. A total of 287 nursing mothers were taken up for the study, who delivered in Obstetric ward. It was an observational study of cross-sectional type. A special Proforma was designed after consultation with experts of various departments (pediatrics, obstetrics, \& community medicine) which included questionnaire for assessing total socio-demographical aspects as well as the knowledge \& practices of mothers regarding breastfeeding before counseling. Observing all principles of verbal \& non-verbal communication, mothers were interrogated.
A written permission from administration \& clearance from ethical committee was obtained. The skills of feeding were assessed by observation of mothers while breastfeeding the baby \& signs of probable difficulty were noted. It was done according to "B-R-E-A-S-TFeeding Observation Form" adapted from H C Armstrong, Training Guide in Lactation Management, New York, IBFAN and UNICEF 1992 [2]. Skills of feeding were assessed on body position \& posture, response of mother, emotional bonding, attachment of baby on breast (good/bad) behaviour, satisfaction, length of one feed etc. Pre-counseling assessment on all aspects was done using the questionnaire of the proforma. Then the counseling was done every day till mother was discharged. Apart from group counseling, one to one counseling of mothers was done on need base, since each mother required reinforcement on different aspects of feeding. When mother was due for discharge her knowledge, practice \& skills on breastfeeding were again reassessed by filling the same proforma. Data obtained, tabulated \& subjected to statistical analysis by SPSS 12 version \& subjected to Chi-square test \& significant difference in mean score was tested using paired t-test while significant difference among pre \& post proportions were tested using McNemar test.

Inclusion Criteria: The study population consists of antenatal \& breastfeeding mothers having a living child whose age is between newborn and two years.

Exclusion Criteria: 1. Women of more than 45 yrs of age \& less than 18 years 2 . Women having children of more than 2 yrs of age.

\section{Observations}

Socio-Demographic Factors: Out of 287 mothers, 94.4\% of mothers were between 20-30 yrs of age. 90.2\% were Hindu $63.8 \%$ were from low socio-economic status. $53.7 \%$ of mothers were illiterate $\&$ out of educated $31 \%$ had primary class \& only $1.4 \%$ of mothers were graduates. $73.9 \%$ were non-working (housewives), of working mothers $(26.1 \%)$ all were unskilled \& daily wage earners. $63 \%$ were from joint -family. $61.3 \%$ of mothers received some facts for infant feeding from mother in -law \& grandmother, 22\% from Anganwadi worker \& dais, while only $16.7 \%$ of mothers received information from doctors( table 5), which clearly indicates that only a small number of mothers received appropriate \& scientific knowledge while rest continue to follow the infant feeding practices which were adopted from family cultures. Family head is still influential for child feeding \& nutrition.

Observation on Knowledge: Only 23\% of mothers gave correct answers for breastfeeding (table 1). The average score of knowledge of mothers before counseling was 3.06 which increased to 9.87 post-counseling (p-value $<0.00)($ Table $2 \&$ Fig 1), showing the statistically significant effect of counseling. The pre-counseling knowledge of mothers revealed that $46 \%$ for first feed, $16 \%$ for Colostrum, $15.7 \%$ for initiation of feeding, $12.2 \%$ frequency of feeds, $29.6 \%$ for night feeds, $23 \%$ for exclusive breastfeeding, $37.6 \%$ for post feeding behaviour gave correct answers. However, statistically highly 
significant improvement ( $\mathrm{p}$-value $<0.01$ ) is observed after counseling for all these aspects (Table 1). Irrespective of various socio-demographic factors, a statistically highly significant improvement ( $\mathrm{p}$-value $<0.01)$ is observed in knowledge of first feed as mother's milk, Colostrum, initiation of feeds, frequency of feeds, night feeds, exclusive breast feeding \& post feeding behaviour. As such overall correct knowledge of mothers was very poor regarding breastfeeding, but the practice of breastfeeding was poorer than the knowledge.

Table 1: Comparison of pre and post counseling knowledge of various aspects of feeding.

\begin{tabular}{|c|c|c|c|c|c|c|}
\hline \multirow[t]{2}{*}{ Aspects } & & \multicolumn{2}{|c|}{ Pre-counseling } & \multicolumn{2}{|c|}{ Post-counseling } & \multirow{2}{*}{$\begin{array}{l}\text { p-value (Mc- } \\
\text { Nemar test) }\end{array}$} \\
\hline & & $\begin{array}{l}\text { No. of } \\
\text { mothers }\end{array}$ & Percent & $\begin{array}{l}\text { No. of } \\
\text { mothers }\end{array}$ & Percent & \\
\hline \multirow[t]{2}{*}{ First- feed } & True & 132 & 46.0 & 285 & 99.3 & \multirow[t]{2}{*}{$<0.01$ or 0.00} \\
\hline & False & 155 & 54.0 & 2 & 0.7 & \\
\hline \multirow[t]{2}{*}{ Colostrum } & True & 46 & 16.0 & 282 & 98.3 & \multirow[t]{2}{*}{$<0.01$ or 0.00} \\
\hline & False & 241 & 84.0 & 5 & 1.7 & \\
\hline \multirow[t]{2}{*}{ Initiation } & True & 45 & 15.7 & 282 & 98.3 & \multirow[t]{2}{*}{$<0.01$ or 0.00} \\
\hline & False & 242 & 84.3 & 5 & 1.7 & \\
\hline \multirow{2}{*}{$\begin{array}{l}\text { Frequency of } \\
\text { Feeding }\end{array}$} & True & 35 & 12.2 & 278 & 96.9 & \multirow[t]{2}{*}{$<0.01$ or 0.00} \\
\hline & False & 252 & 87.8 & 9 & 3.1 & \\
\hline \multirow[t]{2}{*}{ Night feed } & True & 85 & 29.6 & 287 & 100.0 & \multirow[t]{2}{*}{$<0.01$ or 0.00} \\
\hline & False & 202 & 70.4 & 0 & 0.3 & \\
\hline \multirow{2}{*}{$\begin{array}{l}\text { Exclusive-Breast } \\
\text { Feeding }\end{array}$} & True & 66 & 23.0 & 285 & 99.3 & \multirow[t]{2}{*}{$<0.01$ or 0.00} \\
\hline & False & 221 & 77.0 & 2 & 0.7 & \\
\hline
\end{tabular}

Table 2: Comparison of pre and post counseling knowledge scores of mothers.

\begin{tabular}{|l|l|l|l|l|l|}
\hline \multirow{2}{*}{} & \multicolumn{2}{|l|}{ Knowledge Score } & \\
\cline { 2 - 6 } & Minimum & Maximum & Mean Score & Std. Deviation & $\begin{array}{l}\text { p-value of } \\
\text { paired- t test }\end{array}$ \\
\hline Pre-Counseling & & & 3.0697 & 2.11604 & 0.000 \\
\hline Post- Counseling & 0.00 & 9.00 & 9.8746 & 0.54028 & \\
\hline
\end{tabular}

Figure-1: Comparison of knowledge and practice of mothers regarding breast feeding---pre and post counseling.

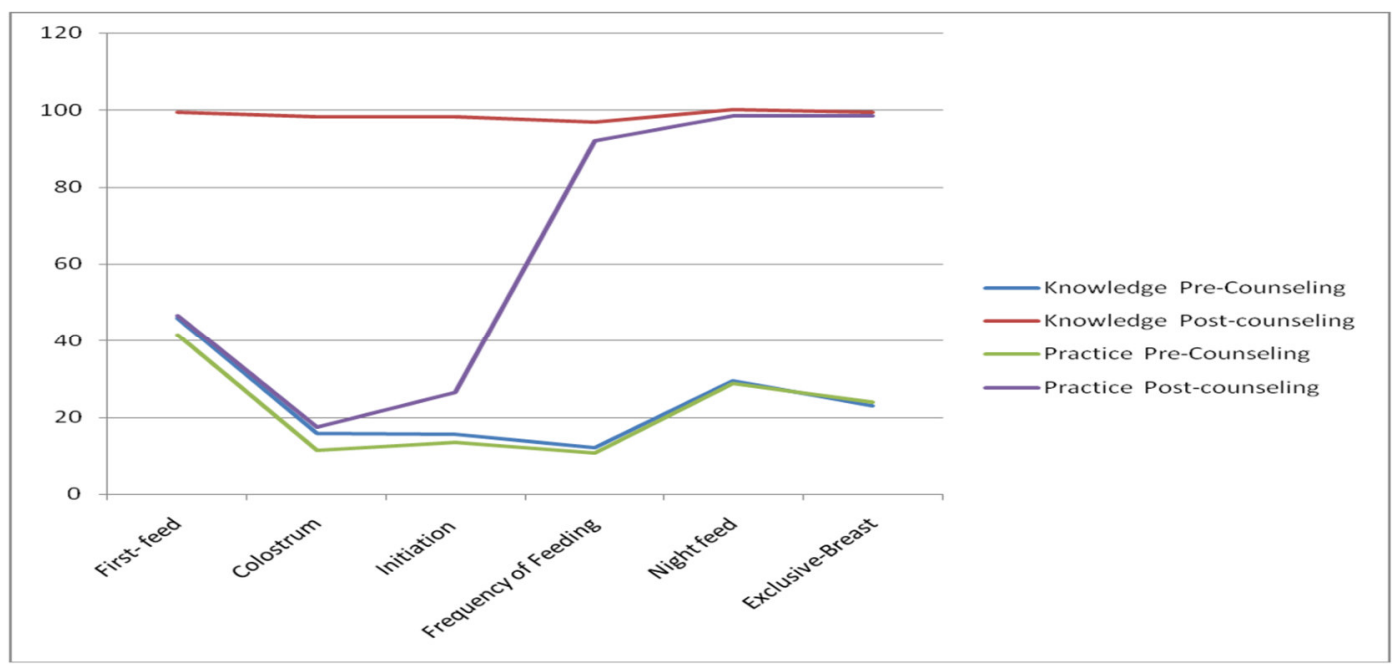


Observation of Practices of Feeding: Only $21.4 \%$ of mothers applied the knowledge of breastfeeding to practice it correctly (table 3). However, statistically highly significant improvement ( $\mathrm{p}$-value $<0.01$ ) was observed in practice of breastfeeding after counseling (Table 3 \& Fig 1). Overall score on practice of breastfeeding before counseling was 3.85 which increased to 8.41 after counseling with p-value of 0.00 (Table 4). On comparing the various aspects of practices amongst demographic variants a statistically highly significant improvement is seen post counseling $(p-v a l u e<0.01)$.

Table 3: Comparison of pre and post counseling practices of mothers regarding various aspects of breast-feeding

\begin{tabular}{|c|c|c|c|c|c|c|}
\hline \multirow[t]{2}{*}{ Aspects } & & \multicolumn{2}{|l|}{ Pre-counseling } & \multicolumn{2}{|l|}{ Post-counseling } & \multirow{2}{*}{$\begin{array}{l}\text { p-value } \\
\text { (Mc-Nemar test) }\end{array}$} \\
\hline & & $\begin{array}{l}\text { No. of Mothers } \\
\text { following } \\
\text { practices }\end{array}$ & Percent & $\begin{array}{l}\text { No. of Mothers } \\
\text { following practices }\end{array}$ & Percent & \\
\hline \multirow[t]{2}{*}{ First- feed } & True & 119 & 41.5 & 134 & 46.7 & \multirow[t]{2}{*}{$<0.01$ or 0.00} \\
\hline & False & 168 & 58.5 & 153 & 53.3 & \\
\hline \multirow[t]{2}{*}{ Colostrum } & True & 33 & 11.5 & 50 & 17.4 & \multirow[t]{2}{*}{$<0.01$ or 0.00} \\
\hline & False & 254 & 88.5 & 237 & 82.6 & \\
\hline \multirow[t]{2}{*}{ Initiation of feed } & True & 39 & 13.6 & 76 & 26.5 & \multirow[t]{2}{*}{$<0.01$ or 0.00} \\
\hline & False & 248 & 86.4 & 211 & 73.5 & \\
\hline \multirow{2}{*}{$\begin{array}{l}\text { Frequency of } \\
\text { Feeding }\end{array}$} & True & 31 & 10.8 & 264 & 92.0 & \multirow[t]{2}{*}{$<0.01$ or 0.00} \\
\hline & False & 256 & 89.2 & 23 & 8.0 & \\
\hline \multirow[t]{2}{*}{ Night feed } & True & 83 & 28.9 & 283 & 98.6 & \multirow[t]{2}{*}{$<0.01$ or 0.00} \\
\hline & False & 204 & 70.7 & 4 & 1.4 & \\
\hline \multirow{2}{*}{$\begin{array}{l}\text { Exclusive-Breast } \\
\text { Feeding }\end{array}$} & True & 69 & 24.0 & 283 & 98.6 & \multirow[t]{2}{*}{$<0.01$ or 0.00} \\
\hline & False & 218 & 76.0 & 4 & 1.4 & \\
\hline
\end{tabular}

Table-4: Scoring of practices of mothers \& difference between pre \& post counseling.

\begin{tabular}{|l|l|l|l|l|l|}
\hline & Minimum & Maximum & Mean Score & Std. Deviation & $\begin{array}{l}\text { p-value of paired-t } \\
\text { test }\end{array}$ \\
\hline $\begin{array}{l}\text { Pre Counseling } \\
\text { Practice score }\end{array}$ & 1.00 & 9.00 & 3.85 & 1.89 & 0.00 \\
\hline $\begin{array}{l}\text { Post Counseling } \\
\text { Practice score }\end{array}$ & 4.00 & 10.00 & 8.41 & 0.80 & \\
\hline
\end{tabular}

Table-5: Various Sources of knowledge.

\begin{tabular}{|l|l|l|}
\hline Source of Knowledge & $\begin{array}{l}\text { Number of } \\
\text { Mothers }\end{array}$ & Percent \\
\hline Mother and others & 176 & 61.3 \\
\hline Anganwadi Workers/Dai & 63 & 22.0 \\
\hline Health Professionals & 48 & 16.7 \\
\hline Total & $\mathbf{2 8 7}$ & $\mathbf{1 0 0 . 0}$ \\
\hline
\end{tabular}

Observation on Skills of Breastfeeding: Skills assessment on breastfeeding was done depending upon B-R-E-A-S-T proforma \& observations were made depending upon the good and bad signs of various components of breastfeeding. The overall score for skills pre-counseling was 0.14 which increased to 2.98 after counseling which was found to be Statistically highly significant(p-value $<0.01)$ (Fig 2). 
Figure-2: Pre \& post counseling comparisons of Breast feeding Skills scores

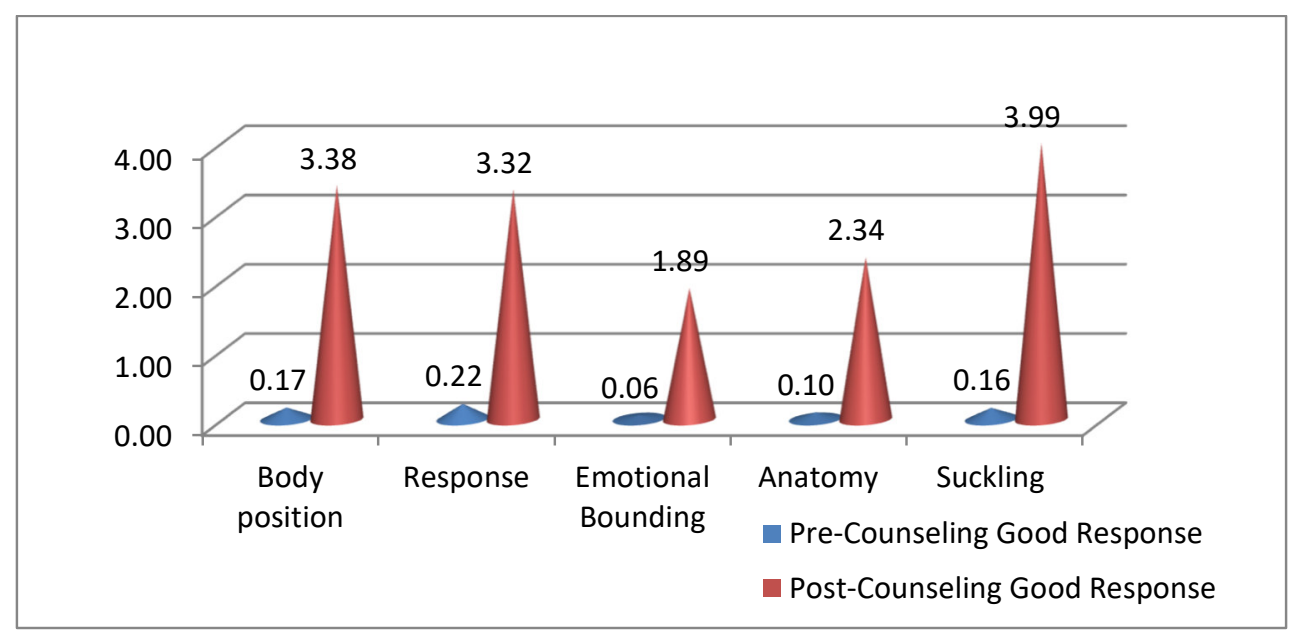

\section{Discussion}

Of 287 mothers studied our observations revealed that majority $(94.4 \%)$, of mothers were in the age group between 20-30. Similar were the observations of $\mathrm{N}$ Das, D Chattopadhyay et al $[9,10,12,14]$. A large majority of mothers were from low \& medium socioeconomic status, $(63.8 \% \& 35.9 \%$ respectively $)$. Similar observation was made by Dr. Sarmila Malik [11] that $75 \%$ mothers were of the socio-economic class III and IV. Observations of Divyarani et al [4] \& N Das, D Chattopadhyay et al [9] were different. Divya rani found that $18.7 \%$ of mothers were below poverty line while Das et al [4, 10] observed only 38.6\% (132/342) belonged to lowest economic class. This could be because only mothers from low socio-economic status prefer to deliver in medical colleges probably to take benefit of the government scheme 'JANNANI SURAKSHA YOJNA' (JSY). 53.7\% of mothers were illiterate \& $31.4 \%$ had primary class education in our study. Contrary to our observations the education status of Sarmila et al [11] \& other [2] study were much better probably these observations were from urban areas compared to the observations of ours study which was from rural population.

$61.3 \%$ mothers from our study received information regarding infant feeding \& child care from mother-inlaw, grand-mother \& other family members \& only $16.7 \%$ from health professionals indicating still motherin-law \& other ladies of the family influence the feeding of infants (Table 5). Rindae et al [10] observed that only $5 \%$ subjects gained information from nurses. While Sushma Sriram [12] \& Brajesh kumar et al [13] revealed $58.67 \%$ \& $58.3 \%$ respectively received counseling from health professionals.

\section{Knowledge \& Practice}

Overall only $23 \%$ of mothers had correct knowledge on total breast feeding, while only $21.4 \%$ practiced it correctly. Only $41.5 \%$ of mothers gave breast milk while $57 \%$ gave some pr-lacteal feeds as first feed to the baby. $16 \%$ for colostrum, $15.7 \%$ for initiation of breast feeding within one hour, $12.2 \%$ for frequency of breastfeeding, $29.6 \%$ for night feeds, $23 \%$ for exclusive breast feeding had correct knowledge on these aspects ( Table 1,2 \& Fig 1), indicating poor knowledge regarding breastfeeding \& a great influence of elderly lady of the family. No difference in knowledge \& practice is observed among various socio-demographic variables. Similar observations made by various workers $[4,5,6,7,8,9,11,12]$. However, these studies were done 5 to 10 yrs ago, indicating not much improvement in knowledge \& practice of mothers on infant feeding has occurred despite Herculean efforts to improve nutrition of infants $\&$ children in last decade.

\section{Skills}

Assessment was based on B-R-E-A-S-T proforma. Overall pre-counseling score of 0.14 increased to 2.98 after counseling, which was statistically highly significant ( $p$-value $<0.00$ ) (Fig 2). No study of this type on skill scoring is presently available for comparison.

\section{Conclusion}

Inappropriate knowledge, practices \& incorrect skills on breast-feeding is still prevalent amongst mothers in general \& particularly in this area of Madhya-Pradesh. Repeated \& effective counseling appears to be only 
answer to improve infant feeding and in-turn to reduce morbidity $\&$ mortality due to malnutrition

\section{Acknowledgement}

I am grateful to Dr. Kamna Nigam for time to time constructive suggestions. Contributors: JS: collected the data $\&$ assisted in manuscript writing; $\mathrm{KN}$ : planned the study, wrote the manuscript \& analyzed the data; JM: assisted in data collection $\&$ analysis.

\section{Source of Support: Nil \\ Conflict of Interest: None \\ Permission of IRB: Yes}

\section{References}

1. National Rural Health Mission .Guidelines for enhancing optimal infant and young child feeding practices. Ministry of Health and Family Welfare Government of India, 2013.

2. World Health Organisation. Contemporary patterns of breast feeding. Report on the WHO Collabrative study on breast feeding. Geneva: WHO; 1981.

3. Sreeramareddy CT, Joshi HS, Sreekumaran BV, Giri $\mathrm{S}$, Chuni N. Home delivery and newborn care practices among urban women in western Nepal: a questionnaire survey. BMC Pregnancy Childbirth. 2006 Aug 23;6:27.

4. Divyarani.D.C . Knowledge, attitude and practice of breastfeeding among mothers in postnatal ward and in mothers attending immunization clinic, bellary, Karnataka; 2013.

5. Kumar G A, Patil VM et al. Breast feeding practices among mothers in urban field practice area of urban medical college, Gulbarga. Journal of pharmaceutical \& biomedical science 2011 April; 04:1-3.

6. Govt. of India. National Family Health survey III (2005-2006). IIPS, Ministry of Health \& Family Welfare; Mumbai. 2007).
7. Kumar D, Agarwal N, Swami HM. Sociodemographic correlates of breast-feeding in urban slums of Chandigarh. Indian J Med Sci. 2006 Nov;60(11):461-6.

8. Lt Col PMP Singh, Col R Bhalwar. Breast Feeding Practices among Families of Armed Forces Personnel in a Large Cantonment. MJAFI 2007; vol. 63, No. 2: 134136).

9. Das N, Chattopadhyay D, Chakraborty S, Dasgupta A. Infant and Young Child Feeding Perceptions and Practices among Mothers in a Rural Area of West Bengal, India. Ann Med Health Sci Res. 2013 Jul;3(3):370-5. doi: 10.4103/2141-9248.117955.

10. John R. Knowledge, attitude and practice of employed mothers about breastfeeding. Nurs J India. 2005 Apr;96(4):85-6.

11. Mallik S. Knowledge of breast feeding and timely initiation of it amongst post natal mothers : An experience from a baby friendly teaching hospital of a metropolitan city IOSR Journal of Dental and Medical Sciences (IOSR-JDMS) e-ISSN: 2279-0853, p-ISSN: 2279-0861. Volume 4, Issue 1 (Jan.- Feb. 2013), PP 2530 www.iosrjournals.org, www.iosrjournals.org.

12. Sriram S, Mehariya KM et al. Knowledge, attitude and practices of mothers regarding infant feeding practices, National journal of medical research, Volume 3 | Issue 2 | Apr - June 2013.

13. Kumar B et al. A study of knowledge attitude and practices of breastfeeding among mothers in Sullia, Rajiv Gandhi university of health sciences, Karnataka, Bangalore; 2011.

14. Dasgupta A. Assessment of Infant and Young Child Feeding Practices among the Mothers in a Slum Area of Kolkata Int J Biol Med Res. 2014; 5(1): 3855-386.

\section{How to cite this article?}

Sonwani J, Mandliya J, Nigam K, Counseling of nursing mothers! How effective it is - For improving nutrition of neonates \& infants : Int J Pediatr Res 2016;3(4):246-251.doi:10.17511/ijpr.2016.i04.07. 